\title{
Development of New High-Performance Visible Light Photoinitiators Based on Carbazole Scaffold and Their Applications in 3D Printing and Photocomposite Synthesis
}

\author{
Mira Abdallah ${ }^{1,2,3}$, Diego Magaldi ${ }^{4}$, Akram Hijazi $^{3}$, Bernadette Graff ${ }^{1,2}$, Frederic Dumur ${ }^{5}$, Jean- \\ Pierre Fouassier ${ }^{1,2}$, Thanh-Tuân Bui ${ }^{4}$, Fabrice Goubard ${ }^{4}$, Jacques Lalevée*1,2 \\ ${ }^{1}$ Université de Haute-Alsace, CNRS, IS2M UMR 7361, F-68100 Mulhouse, France \\ ${ }^{2}$ Université de Strasbourg, France \\ ${ }^{3}$ EDST, Université Libanaise, Campus Hariri, Hadath, Beyrouth, Liban. \\ ${ }^{4}$ Laboratoire de Physicochimie des Polymères et des Interfaces, Université de Cergy-Pontoise, 5 \\ mail Gay Lussac, 95000 Neuville-sur-Oise, France. \\ 5 Aix Marseille Univ, CNRS, ICR UMR 7273, F-13397 Marseille, France \\ *Corresponding author : jacques.lalevee@uha.fr
}

\begin{abstract}
:
In this article, new compounds based on the carbazole scaffold (DMs = DM1 and DM2) were synthesized and proposed as high performance visible light photoinitiators/photosensitizers for both the free radical polymerization (FRP) of methacrylates and the cationic polymerization (CP) of epoxides upon visible light exposure using LED@405 nm. In the presence of diaryliodonium salts, excellent polymerization rates and high final conversions were obtained. Remarkably, DM2 leads to higher final conversions than DM1. The photophysical and photochemical properties of the carbazole derivatives were studied in terms of light absorption, steady state photolysis and fluorescence spectroscopy. Photosensitization/photoinitiation mechanisms of the carbazole derivatives were discussed from fluorescence quenching, redox behavior, and cyclic voltammetry experiments. A full picture of the involved chemical mechanisms is provided. The photosensitization of the carbazole derivatives occurred predominantly via singlet excited states at the rate of the diffusion limit. The high performance of DMs in initiating systems is also well shown for new 3D resins upon exposure to laser diode at $405 \mathrm{~nm}$ for laser write experiments. Remarkably, DM2 can also be used in photocomposite synthesis using LED-conveyor.
\end{abstract}


KEYWORDS: composites; light-emitting diodes; photoinitiators; photopolymerization; 3D resins.

\section{INTRODUCTION}

The UV-curing process is a polymerization technique that allows a fast radiation induced transformation of liquid systems into solid polymers. Radical or cationic species are generated by interaction of light with a photoinitiator; these latter species induce the polymerization reaction of suitable reactive monomers and oligomers [1]. Because of many advantages (low temperature of usage (usually room temperature), low emission of volatile organic compounds, low energetic consumption, no solvents added etc.), the polymerization processes triggered or controlled by light are the subject of huge efforts [2-6]. More particularly, the developments of photosensitive systems that can operate at safer (longer) wavelengths than UV light are currently actively researched. All of these works are strongly supported by the development of new irradiation systems and especially of the light emitting diodes (LEDs) that can represent very convenient irradiation devices compared to UV lamps (e.g., mercury lamp) or UV laser (see some examples in refs [2] and [7-14]).

Recently, we found that carbazole based compounds successfully interacted with triarylsulfonium and diaryliodonium salts, leading to the cationic polymerization of epoxides and the free radical polymerization of methacrylates upon near-UV irradiation [15-19]. The high efficiency of carbazole derivatives towards the onium salts (even at low concentration) was ascribed to a highly efficient sensitization reaction [15-19]. To enhance the absorption of the carbazole compounds at longer wavelengths, carbazole derivatives with the extension of their $\pi$ system (such as DM1 and DM2) are designed and developed in this work (Scheme 1). 
Therefore, we report here the synthesis of new carbazole derivatives (noted DMs) and their use in order to achieve both high photopolymerization rates and high final conversions. They are also investigated to shed some light on the structure/reactivity/efficiency relationship for their ability to initiate free radical polymerization (FRP) and/or cationic polymerization $(\mathrm{CP})$ process under visible light delivered by LEDs at, for example, @375; and @405 nm.

Parallel to this, 3D printing technologies have been explored for a wide range of applications including robotics, automobile components, firearms, medicine, space, etc. Some examples include 3D printed components being employed in autonomous underwater (or surface) vehicles; 3D printed coral reef replicas being used to restore damaged coral reefs [20]. 3D Printing has also found astonishing applications in research fields ranging from 3D food printing [21], radiology [22], and 3D organ printing technology (Biomedical Engineering) [23]. Composite materials have found numerous applications e.g. in sports equipments [24], solar energy applications [25], aerospace applications [26,28], ground transportation [27], and automotive industries [28].

In this context (3D printing and composites), the development of photosensitive resins upon near UV or visible light is highly desired. Therefore, example of the performance of the DM1/Iodonium salt couple as a radical photoinitiating system in new radical 3D resins upon exposure to laser diode under air is given here. As well, the manufacture of thick glass fibers/methacrylate resin composites using the DM2/NPG couple as a radical photoinitiating system is also displayed, and the preparation of the composites is discussed too. 

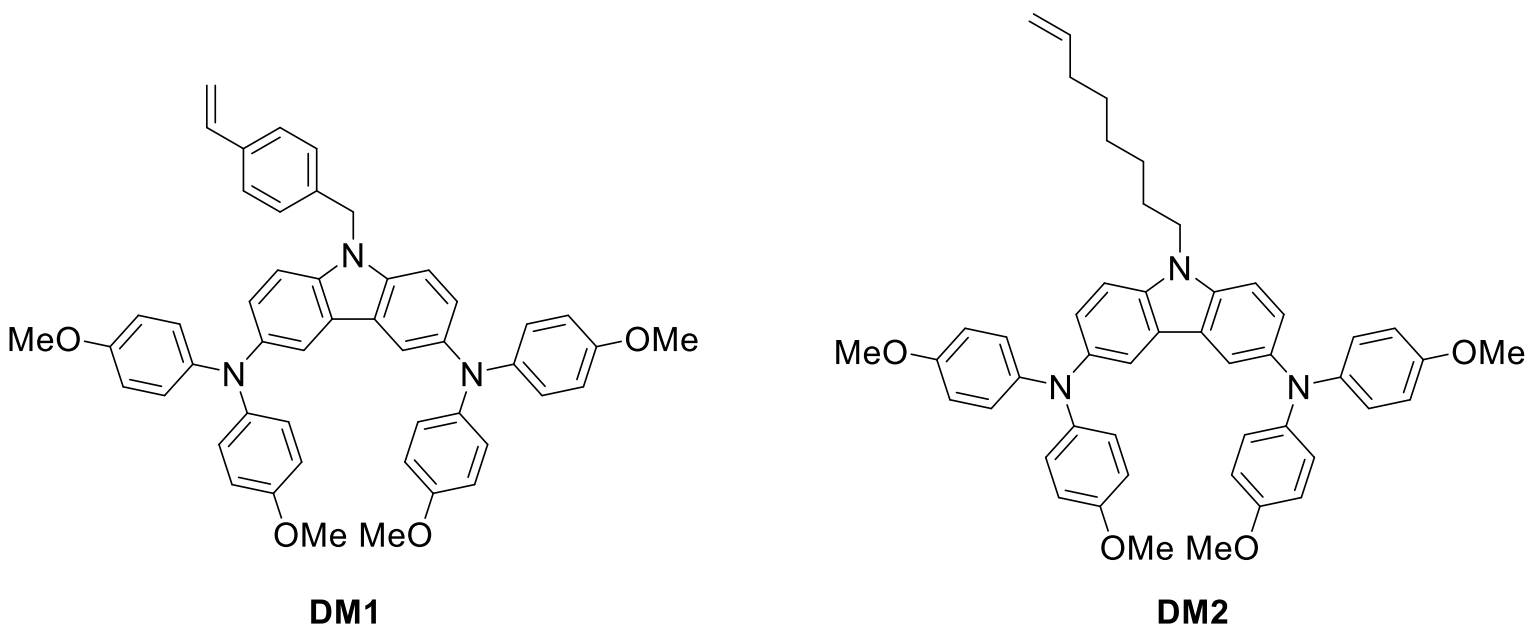

Scheme 1. Chemical structures of photoinitiators investigated in this study.

\section{EXPERIMENTAL PART}

\subsection{Synthesis of DM1 and DM2}

The synthetic routes toward the different targeted molecules are outlined in Scheme 2, using the same synthetic approach as reported in our previous work for similar compounds [29]. Briefly, carbazole molecules were synthesized from commercially available 3,6-dibromocarbazole using a common two-step synthesis. These $N$-alkyl/benzyl-substituted 3,6-dibromocarbazole intermediates $\mathbf{1 a - 1 b}$ have been isolated in high yields by the $N$-alkylation/benzylation reaction in strong basic medium. The second step involved a classical twofold Pd-catalyzed BuchwaldHartwig amination between the freshly synthesized $N$-substituted carbazole derivatives $\mathbf{1 a - 1 b}$ and the commercial product di(4-methoxyphenyl)amine. These final compounds DM1-DM2 were obtained as yellowish powders in reasonable yields after purification. 


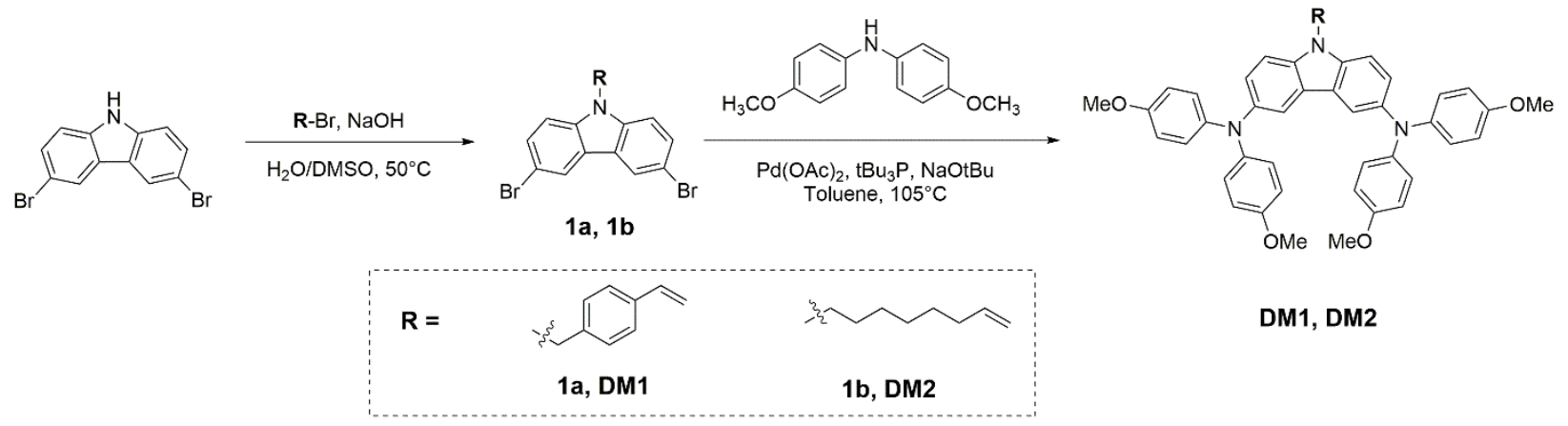

Scheme 2. Synthesis of the two studied compounds (DM1, DM2).

General synthesis procedure for $\mathbf{1 a - 1 b}$

In a dry $100 \mathrm{~mL}$ round-bottom flask, 3,6-dibromocarbazole (0.6 mmol), 1-bromoalkene (0.9 mmol), $\mathrm{NaOH}$ solution (4.7 mmol, dissolved in $1 \mathrm{~mL}$ of water), and DMSO (6 mL) were charged. The mixture was heated to $50^{\circ} \mathrm{C}$ for $4 \mathrm{~h}$ and allowed to cool to room temperature. The reaction mixture was quenched with brine $(10 \mathrm{~mL})$ and extracted with $\mathrm{CH}_{2} \mathrm{Cl}_{2}(3 \times 15 \mathrm{~mL})$. The organic layers were combined, washed with brine and water, dried over anhydrous $\mathrm{MgSO}_{4}$, filtered, and concentrated under reduced pressure. The crude product was purified by column chromatography eluting with $\mathrm{CH}_{2} \mathrm{Cl}_{2} /$ petroleum ether (4/6 v/v) to yield the title compounds as white solids (85\% yield).

$N$-(4-vinylbenzyl)-3,6-dibromocarbazole (1a): ${ }^{1} \mathbf{H}$ NMR $250 \mathrm{MHz}\left(\mathrm{DMSO}-\mathrm{d}_{6}\right) \delta 5.2\left(\mathrm{~d}, 1 \mathrm{H}_{\text {cis, }}\right.$ $\mathrm{J}=11 \mathrm{~Hz}), 5.67(\mathrm{~s}, 2 \mathrm{H}), 5.74\left(\mathrm{~d}, 1 \mathrm{H}_{\text {trans, }} \mathrm{J}=18 \mathrm{~Hz}\right), 6.35(\mathrm{dd}, 1 \mathrm{H}, \mathrm{J}=11$ and $17 \mathrm{~Hz}), 7.10(\mathrm{~d}$, $2 \mathrm{H}, \mathrm{J}=9 \mathrm{~Hz}), 7.36(\mathrm{~d}, 2 \mathrm{H}, \mathrm{J}=8 \mathrm{~Hz}), 7.63(\mathrm{~m}, 4 \mathrm{H}), 8.85(\mathrm{~m}, 2 \mathrm{H}) .{ }^{13} \mathbf{C}\left\{{ }^{1} \mathbf{H}\right\} \mathbf{N M R} 62.9 \mathrm{MHz}$ (DMSO-d $)$ ); $\delta$ (ppm) 45.6, 111.7, 112.0, 114.38, 123.1, 123.6, 126.4, 127.0, 129.0, 136.1, 136.4, 136.8, 139.2.

$N$-(7-octenyl)- 3,6-dibromo-carbazole (1b): ${ }^{1} \mathrm{H}$ NMR 250MHz (DMSO-d $\left.{ }_{6}\right) \delta 1.32(\mathrm{~m}, 6 \mathrm{H}), 1.83$ (m, 2H), $2.0(\mathrm{~m}, 2 \mathrm{H}), 4.24$ (t, 2H, J = 8.5 Hz ), 4.9-4.95 (m, 1Hcis), 5.0-4.98 (m, 1H trans), 5.76 (m, $1 \mathrm{H}), 7.26\left(\mathrm{~d}, 2 \mathrm{H}, \mathrm{J}_{\mathrm{o}}=10.5 \mathrm{~Hz}\right), 7.55\left(\mathrm{dd}, 2 \mathrm{H}, \mathrm{J}_{\mathrm{o}}=10.5 \mathrm{~Hz}, \mathrm{~J}_{\mathrm{m}}=2.4 \mathrm{~Hz}\right), 8.42\left(\mathrm{~d}, 2 \mathrm{H}, \mathrm{J}_{\mathrm{m}}=2.4 \mathrm{~Hz}\right)$. ${ }^{13} \mathbf{C}\left\{{ }^{1} \mathbf{H}\right\}$ NMR 62.9 MHz (DMSO-d 6$) ; \delta$ (ppm) 27.1, 28.7, 28.8, 28.8, 33.6, 43.3, 110.4, 111.9, $114.5,123.6,123.4,129.0,138.8,139.3$. 
General synthesis procedure for compounds DM1 and DM2.

In a dry Schlenk, $1 \mathbf{a}$ or $\mathbf{1 b}(1.0 \mathrm{mmol})$, bis(4-methoxyphenyl)amine (3.0 mmol), palladium(II) acetate $(0.05 \mathrm{mmol})$, sodium tert-butoxide $(4.0 \mathrm{mmol})$, tri-tert-butylphosphine $(0.1 \mathrm{mmol}$, dissolved in $1 \mathrm{~mL}$ of toluene) and anhydrous toluene $(10 \mathrm{~mL})$ were charged. The septum-sealed Schlenk was evacuated and refilled with Argon five times. The mixture was stirred under an argon atmosphere in sealed Schlenk tubes at $105^{\circ} \mathrm{C}$ for $80 \mathrm{~h}$ and allowed to cool to room temperature. The reaction mixture was diluted with AcOEt $(75 \mathrm{~mL})$ and washed with water $(\times 3)$ and brine $(\times$ 1), dried over anhydrous $\mathrm{MgSO}_{4}$, filtered, and concentrated under reduced pressure to give a viscous oil (ca. 2-3 mL). This crude product was purified by fast column chromatography eluting with $\mathrm{CH}_{2} \mathrm{Cl}_{2}$. The collected fractions were combined and the solvent was removed under vacuum to give an oil product which was added to methanol $(200 \mathrm{~mL})$ with vigorous stirring to precipitate the product. The precipitate was then filtered off, rinsed with methanol several times and purified again by silica gel column 4/1 hexane/AcOEt to yield a $68 \%$ of a yellowish amorphous solid.

\section{$N$-(4-benzyl-6-vinyl)-3,6-bis(4,4'-dimethoxydiphenylaminyl)carbazole (DM1):}

Elemental Analysis (\%) Calculated C 79.76, H 5.87, N 5.69, O 8.67. Found C 78.35, H 5.88, N 5.4, O 8.2;

${ }^{1}$ H NMR $250 \mathrm{MHz}\left(\mathrm{DMSO}_{-} \mathrm{d}_{6}\right) \delta 3.72(\mathrm{~s}, 12 \mathrm{H}), 5.25\left(\mathrm{~d}, 1 \mathrm{H}, \mathrm{J}_{\text {trans }}=12.6 \mathrm{~Hz}\right), 5.08\left(\mathrm{~d}, 1 \mathrm{H}, \mathrm{J}_{\mathrm{cis}}=\right.$ $20.4 \mathrm{~Hz}), 6.71\left(\mathrm{dd}, 1 \mathrm{H}, \mathrm{J}_{\text {cis }}=22.05 \mathrm{~Hz}, \mathrm{~J}_{\text {trans }}=13.5 \mathrm{~Hz}\right), 6.82-6.91(\mathrm{~m}, 16 \mathrm{H}), 7.12\left(\mathrm{dd}, 2 \mathrm{H}, \mathrm{J}_{\mathrm{o}}=\right.$ $\left.10.3 \mathrm{~Hz}, \mathrm{~J}_{\mathrm{m}}=2.9 \mathrm{~Hz}\right), 7.25\left(\mathrm{~d}, 2 \mathrm{H}, \mathrm{J}_{\mathrm{o}}=9.6 \mathrm{~Hz}\right), 7.44\left(\mathrm{~d}, 2 \mathrm{H}, \mathrm{J}_{\mathrm{o}}=9.9 \mathrm{~Hz}\right), 7.58\left(\mathrm{~d}, 2 \mathrm{H}, \mathrm{J}_{\mathrm{o}}=10.5\right.$ $\mathrm{Hz}), 7.73\left(\mathrm{~d}, 2 \mathrm{H}, \mathrm{J}_{\mathrm{m}}=2.1 \mathrm{~Hz}\right)$.

${ }^{13} \mathbf{C}\left\{{ }^{1} \mathbf{H}\right\}$ NMR 62.9 MHz (DMSO-d 6 ); $\delta$ (ppm) 55.2 (4C), 55.7, 114.6 (8C), 116.4, 116.8, 119.9 (2C), 120.9 (2C), 122.8 (2C), 123.7 (8C), 126.4 (2C), 127.2 (2C), 136.2, 132.3 (2C), 137.6, 140.3, $140.8(2 \mathrm{C}), 142.1(4 \mathrm{C}), 154.2(4 \mathrm{C})$.

\section{N-(7-octene)-3,6-bis(4,4'-dimethoxydiphenylaminyl)carbazole (DM2)}

Elemental Analysis (\%) Calculated C 78.77, H 6.75, N 5.74, O 8.74. Found C 78.11, H 6.85, N 5.47, O 7.96 .

HR-MS: $\mathrm{m} / \mathrm{z}=737.3254[\mathrm{M}+\mathrm{H}]^{+}$ 
${ }^{1}$ H NMR $250 \mathrm{MHz}\left(\mathrm{DMSO}_{-} \mathrm{d}_{6}\right) \delta 1.28(\mathrm{~s}, 6 \mathrm{H}), 1.73(\mathrm{~s}, 2 \mathrm{H}), 1.93(\mathrm{~s}, 12), 3.67(\mathrm{~s}, 12 \mathrm{H}), 4.28(\mathrm{~m}$, $2 \mathrm{H}), 4.87-4.91\left(\mathrm{~m}, 1 \mathrm{H}_{\mathrm{cis}}\right), 4.97$ (m, $\left.1 \mathrm{H}_{\text {trans }}\right), 5.69-5.75(\mathrm{~m}, 1 \mathrm{H}), 6.76-6.86(\mathrm{~m}, 16 \mathrm{H}), 7.09(\mathrm{~d}, 2 \mathrm{H})$, $7.47(\mathrm{~d}, 2 \mathrm{H}), 7.64(\mathrm{~s}, 2 \mathrm{H})$.

${ }^{13} \mathbf{C}\{1 \mathbf{H}\}$ NMR $62.9 \mathrm{MHz}$ (DMSO-d $\mathrm{d}_{6}$ ); $\delta$ (ppm) 23.6, 28.2, 28.3, 28.7, 33.1, 42.5, 55.2, 110.3, 114.6, 116.6, 122.6, 123.6, 124.4, 131.1, 137.2, 138.7, 139.9, 140.1, 154.1.

\subsection{Other Chemical Compounds.}

The other chemicals compounds (Scheme 3) ( $N$-phenylglycine NPG as well as the radical monomers (BisGMA and TEGDMA)) were obtained from Sigma-Aldrich, they were selected from the highest purity available. The iodonium salt (Iod) was obtained from Lambson Ltd (UK); the epoxy monomer (EPOX) was obtained from Allnex.

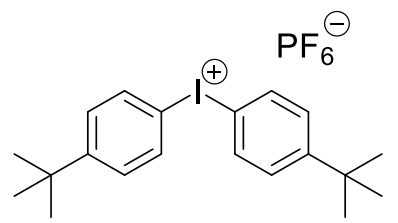

Speedcure 938 (lod)<smiles>O=C(O)CNc1ccccc1</smiles>

N-phenylglycine (NPG)<smiles>O=C(OCC1CCC2OC2C1)C1CCC2OC2C1</smiles>

EPOX<smiles>C=C(C)C(=O)OCC(O)COc1ccc(C(C)(C)c2ccc(OCC(O)COC(=O)C(=C)C)cc2)cc1</smiles>

BisGMA<smiles>C=C(C)C(=O)OCCOCCOCCOC(=O)C(=C)C</smiles>

TEGDMA

Scheme 3. Other used chemical compounds.

\subsection{Irradiation Sources.}


The following Light Emitting Diodes (LEDs) were used as irradiation sources: (i) LED@375 nm-incident light intensity at the sample surface: $\mathrm{I}_{0}=40 \mathrm{~mW} \cdot \mathrm{cm}^{-2}$; (ii) LED@405nm ( $\mathrm{I}_{0}=110$ $\left.\mathrm{mW} \cdot \mathrm{cm}^{-2}\right)$.

\subsection{Cationic Photopolymerization (CP) and Free Radical Photopolymerization (FRP).}

The two-component photoinitiating systems (PISs) are mainly based on Photoinitiator/Iodonium salt $[(0.5 \% / 1 \% \mathrm{w} / \mathrm{w})$ or $(0.3 \% / 1 \% \mathrm{w} / \mathrm{w})]$ or Photoinitiator/NPG $(0.5 \% / 1 \% \mathrm{w} / \mathrm{w})$. The weight percent of the different chemical compounds of the photoinitiating system is calculated from the monomer content $(w / w)$. The photosensitive thin formulations ( 25 $\mu \mathrm{m}$ of thickness) were deposited on $\mathrm{a} \mathrm{BaF}_{2}$ pellets under air for the $\mathrm{CP}$ of EPOX. The evolution of the epoxy group content was continuously followed by real time FTIR spectroscopy (JASCO FTIR 4100) at about $790 \mathrm{~cm}^{-1}$, as in ref. [30].

The $1.4 \mathrm{~mm}$ thick samples of BisGMA/TEGDMA were also polymerized under air. The evolution of the methacrylate characteristic peak for the thick samples $(1.4 \mathrm{~mm})$ was followed in the near-infrared range at $\sim 6160 \mathrm{~cm}^{-1}$. The procedure used to monitor the photopolymerization profile has been described in detail in [7,31,32].

\subsection{Free Energy Calculations for Electron Transfer.}

The free energy change $\Delta \mathrm{G}_{\mathrm{et}}$ for an electron transfer reaction was calculated from the classical free-energy change equation (eq 1) [33], where $\mathrm{E}_{\mathrm{ox}}, \mathrm{E}_{\mathrm{red}}$, $\mathrm{E}_{\mathrm{S}}$, and $\mathrm{C}$ are the oxidation potential of the electron donor, the reduction potential of the electron acceptor, the excited state energy and the coulombic term for the initially formed ion pair, respectively. C is neglected as usually done in polar solvents.

$$
\Delta G_{\text {et }}=E_{o x}-E_{r e d}-E_{S}+C
$$




\subsection{ESR Spin-Trapping (ESR-ST) Experiments.}

The ESR-ST experiments were carried out using an X-Band spectrometer (Magnettech). LED@405 nm was used as irradiation source for triggering the production of radicals at room temperature (RT) under $\mathrm{N}_{2}$ in tert-butylbenzene and trapped by phenyl- $N$-tert-butylnitrone (PBN) according to a procedure described by us in $[31,32]$. The ESR spectra simulations were carried out with the PEST WINSIM program.

\subsection{UV-visible absorption and Photolysis Experiments.}

The absorbance properties of the different compounds were studied using JASCO V730 UVvisible spectrometer. In fact, the photolysis can occur by illumination with various LEDs, but LED@375nm was chosen as a template.

\subsection{Fluorescence Experiments.}

The fluorescence properties of the compounds were studied using a JASCO FP-6200 spectrofluorometer.

\subsection{Computational Procedure.}

Molecular orbital calculations were carried out with the Gaussian 03 suite of programs. The electronic absorption spectra for the different compounds were calculated with the time-dependent density functional theory at the MPW1PW91-FC/6-31G* level of theory on the relaxed geometries calculated at the UB3LYP/6-31G* level of theory.

\subsection{D Printing/laser write Experiments.}


For laser write experiments, a laser diode @ $405 \mathrm{~nm}$ (spot size around $50 \mu \mathrm{m}$ ) was used for the spatially controlled irradiation. Rather similar intensity on the surface of the sample and similar emission spectrum for the laser used in 3D printing and the LED in kinetic experiments were used for sake of comparison. The photosensitive resin (various thickness) was polymerized under air and the generated 3D patterns analyzed by a numerical optical microscope (DSX-HRSU from OLYMPUS corporation).

\subsection{UV conveyor.}

The Dymax-UV conveyor was used to cure composites. The glass fibers were impregnated with the organic resin $(50 / 50 \mathrm{w} / \mathrm{w} \%)$ and then irradiated. The UV conveyor is equipped with a 120 mm wide Teflon-coated belt and one UV lamp (mercury-Fe doped lamp). The distance between the lamp and the belt can be manually adjusted (fixed at $15 \mathrm{~mm}$ ) as can the belt speed (fixed at 2 $\left.\min ^{-1}\right)$.

\section{RESULTS AND DISCUSSION}

\subsection{Light Absorption Properties of the Investigated Compounds.}

The absorption spectra of the new proposed photoinitiators (DM1 and DM2) in acetonitrile are reported in the Figure 1. These compounds are characterized by i) a main band, which possesses extremely high extinction coefficients in the near UV and (ii) one additional band at higher wavelengths, which possesses lower extinction coefficients (e.g., DM1 $\sim 4200 \mathrm{M}^{-1} . \mathrm{cm}^{-1}$ at $\lambda_{\max }=$ $300 \mathrm{~nm}$ (main band) and $\sim 5780 \mathrm{M}^{-1} \cdot \mathrm{cm}^{-1}$ at $\lambda=370 \mathrm{~nm}$ (additional band)). The light absorption properties of DM1 and DM2 are summarized in Table 1. Remarkably, their absorptions are intense in the 250-450 spectral range ensuring fairly good overlap with the emission spectra of the near 
UV or visible LEDs used in this work (e.g., @375 and @405 nm). The presence of styrene substituent on the nitrogen (DM1) plays only a slightly role on the light absorption properties in the near UV (compared to an aliphatic chain substituent for DM2), a slight hyperchromic shift is observed for DM1 compared to DM2 as a result of the presence of this electron-donating substituent (Figure 1). The influence of the substitution pattern of DM1 and DM2 is not observed in the visible region. The optimized geometries as well as the frontier orbitals (Highest Occupied Molecular Orbital (HOMO) and Lowest Unoccupied Molecular Orbital (LUMO)) are shown in Figure 2. Both the HOMO and LUMO are strongly delocalized all over the $\pi$ system clearly showing $\pi \rightarrow \pi^{*}$ lowest energy transitions.

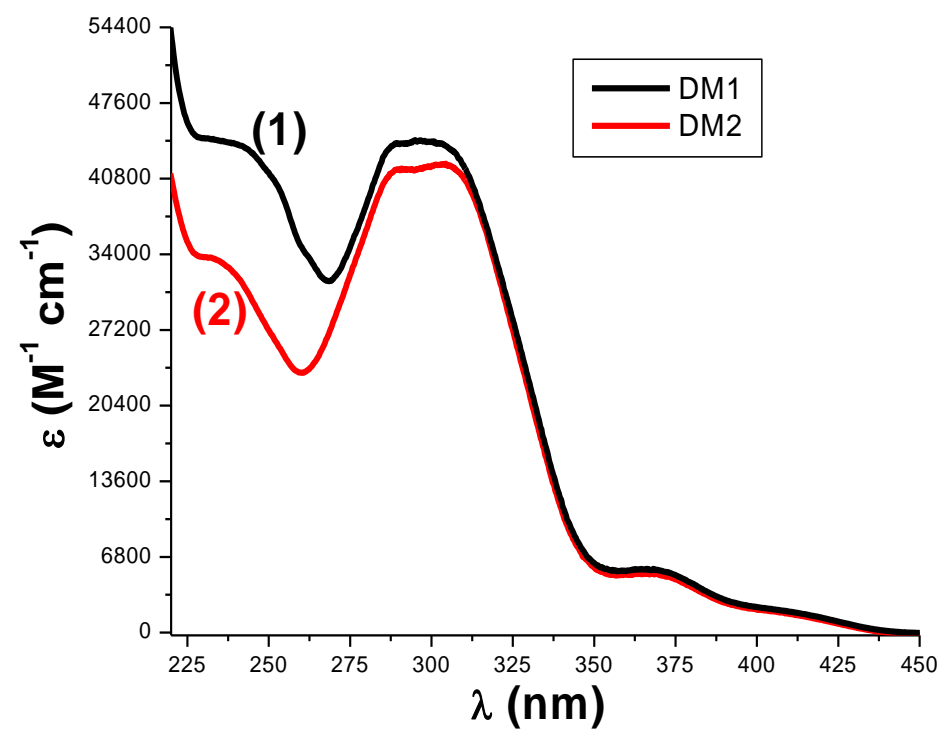

Figure 1. Absorption spectra of the investigated compounds in acetonitrile: (1) DM1; (2) DM2. 
Table 1. Light absorption properties of DM1 and DM2: maximum absorption wavelengths $\lambda_{\max }$, extinction coefficients at $\lambda_{\max }$ and extinction coefficients at the emission wavelength of the LED@405 nm.

\begin{tabular}{|c|c|c|c|}
\hline PI & $\lambda_{\max }(\mathrm{nm})$ & $\varepsilon_{\max }\left(\mathrm{M}^{-1} \cdot \mathrm{cm}^{-1}\right)$ & $\varepsilon(405 \mathrm{~nm})\left(\mathrm{M}^{-1} \cdot \mathrm{cm}^{-1}\right)$ \\
\hline DM1 & 300 & 44200 & 2030 \\
\hline DM2 & 300 & 41900 & 1900 \\
\hline
\end{tabular}

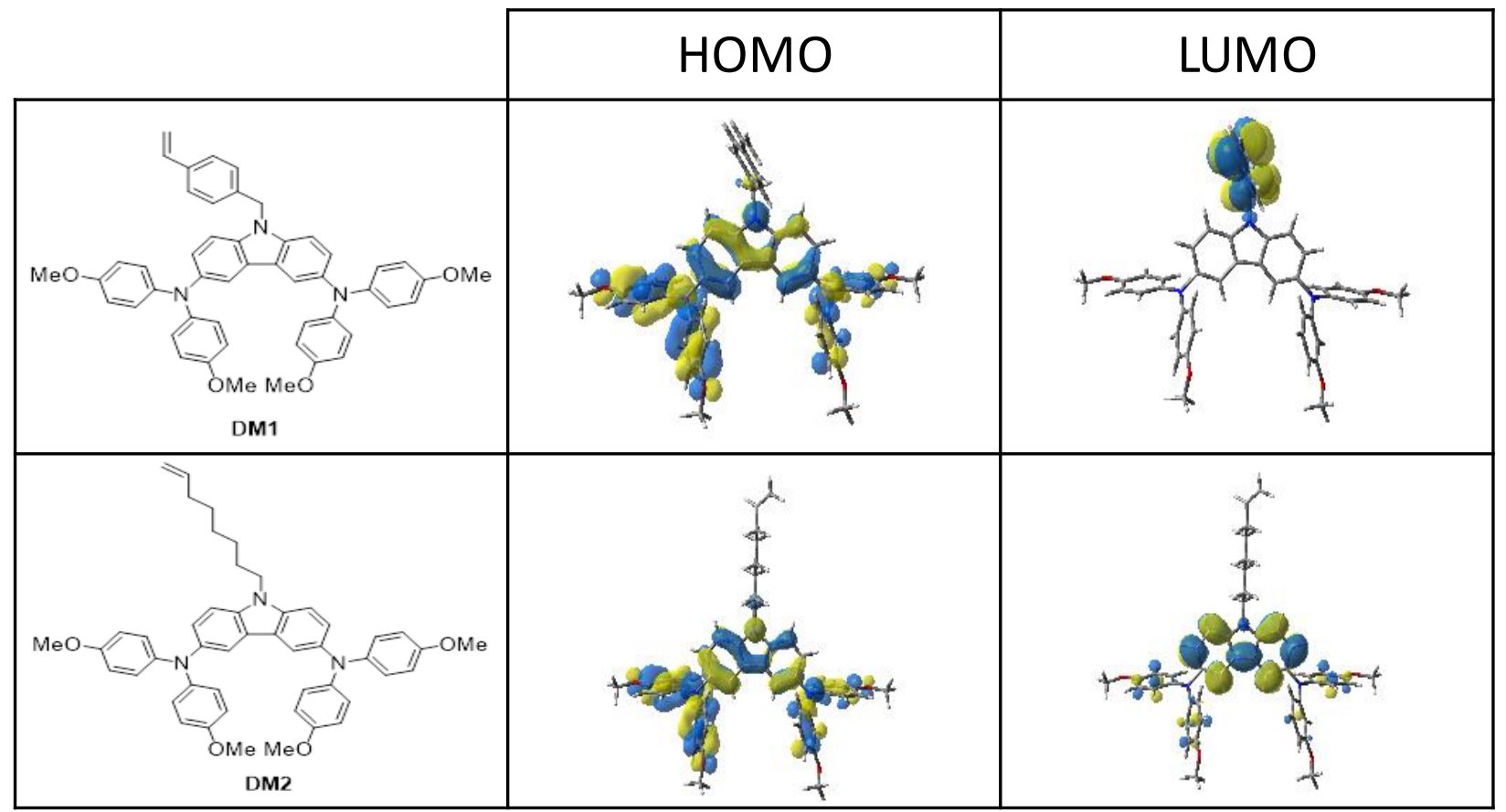

Figure 2. Contour plots of HOMOs and LUMOs for DM1 \& DM2 structures optimized at the B3LYP/6-31G* level of theory.

\subsection{Cationic Polymerization (CP) of Epoxides.}

The CP of $25 \mu \mathrm{m}$ thin epoxide films (e.g., EPOX) under air exhibits a very high efficiency in term of final epoxy function conversion (FC), e.g. FC $=64 \%$ with DM2 (Figure 3A, curve 4; Table 2), using a two-component photoinitiating system based on DM2/Iod combination $(0,5 \% / 1 \% \mathrm{w} / \mathrm{w})$ (irradiation with the LED@ $405 \mathrm{~nm})$. The same holds true at lower concentrations of DM2 e.g. $\mathrm{FC}=56 \%$ with $\mathrm{DM} 2 / \operatorname{Iod}(0,3 \% / 1 \%$ w/w/); Figure $3 \mathrm{~A}$, curve 2 ; Table 2. In these 
irradiation conditions, for Iod alone, no polymerization occurs showing the role of DM1 and DM2 in the global performance of the system. In the same context, lower final epoxy function conversions were obtained when using DM1/Iod combination as photoinitiating system e.g. $\mathrm{FC}=$ $52 \%$ with DM1 (0,5\%/1\% w/w/); (Figure 3A, curve 3; Table 2) and FC = 42\% with DM1 $(0,3 \% / 1 \% \mathrm{w} / \mathrm{w} /)$; (Figure 3A, curve 1; Table 2), despite the same absorption properties for DM1 and DM2 @ $405 \mathrm{~nm}$, and nearly the same electron transfer quantum yield ( $\phi_{\mathrm{et}} ;$ calculated according to eq 2, Table 4 - see below). Therefore, this suggests that the initiating ability of DM2 ${ }^{\bullet+}$ for the polymerization of EPOX is higher than for $\mathrm{DM} 1^{\bullet+}$ (see below in the chemical mechanism in part 3.6).

In addition, a new peak ascribed to the formation of the polyether network during the photopolymerization arises at $\sim 1080 \mathrm{~cm}^{-1}$ in the FTIR spectra (Figure 3B\&C). Therefore, DMs can be considered as a good photoinitiator in combination with an iodonium salt. 
(A)

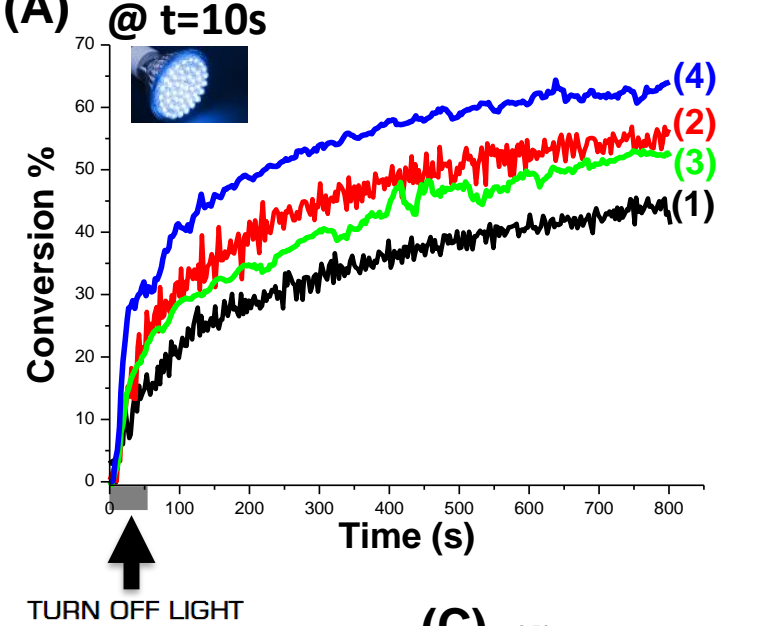

TURN OFF LIGHT

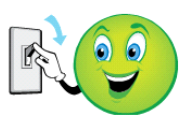

(C)
(B)
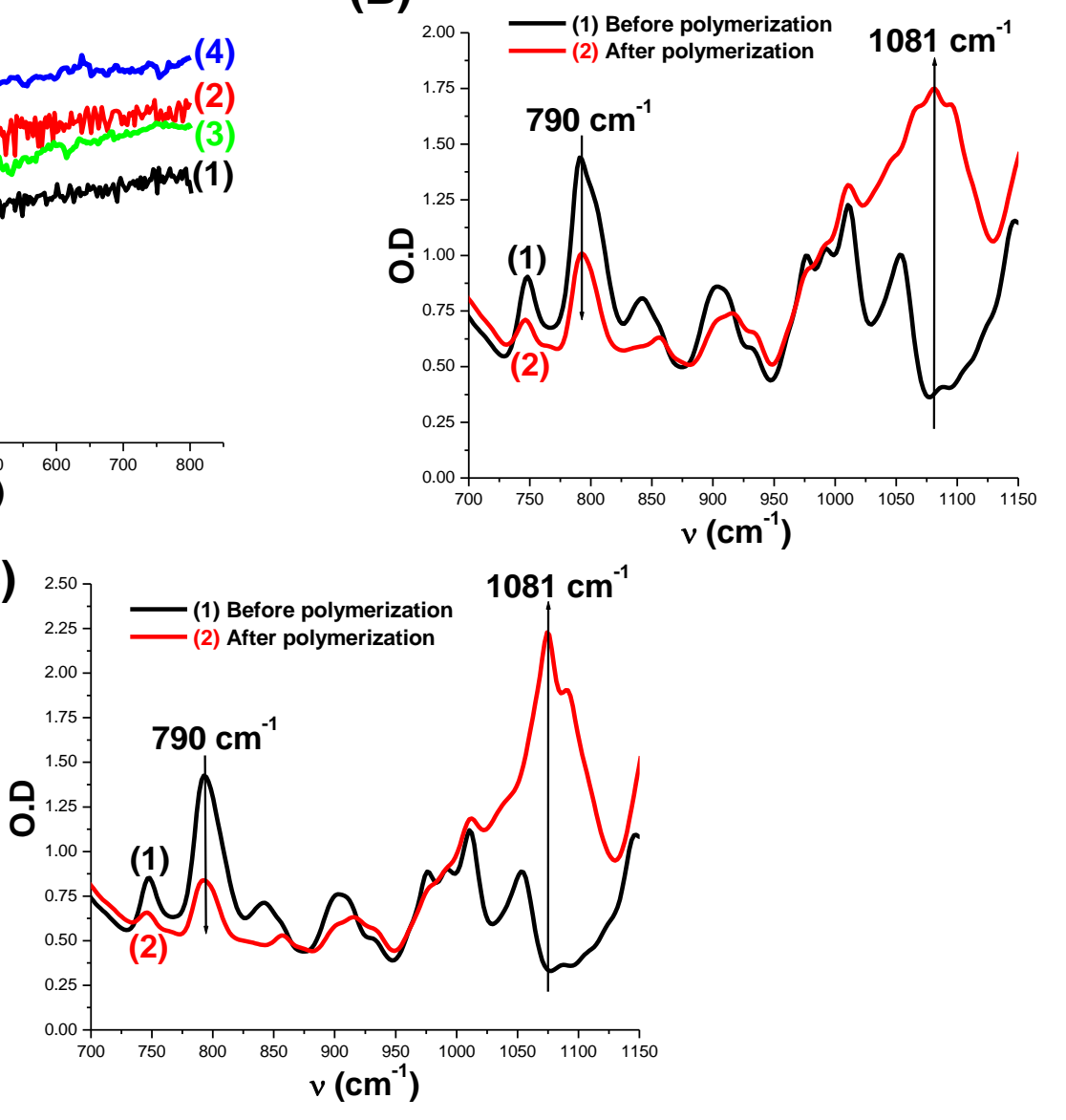

Figure 3. (A): Polymerization profiles (epoxy function conversion vs irradiation time) for EPOX under air (thickness $=25 \mu \mathrm{m}$ ) upon exposure to LED@405 nm in the presence of the twocomponent photoinitiating systems: (1): DM1/Iod $(0.3 \% / 1 \% \mathrm{w} / \mathrm{w}) ;(2): \mathrm{DM} 2 / \mathrm{Iod}(0.3 \% / 1 \% \mathrm{w} / \mathrm{w})$; (3): DM1/Iod $(0.5 \% / 1 \% \mathrm{w} / \mathrm{w})$; and (4): DM2/Iod $(0.5 \% / 1 \% \mathrm{w} / \mathrm{w})$. The irradiation starts for $\mathrm{t}=$ 10s. (B): IR spectra recorded before and after polymerization for DM1/Iod $(0.5 \% / 1 \%$ w/w) upon exposure to LED@405 nm. (C): IR spectra recorded before and after polymerization for DM2/Iod $(0.5 \% / 1 \% \mathrm{w} / \mathrm{w})$ upon exposure to LED@405 nm. 


\subsection{Free radical photopolymerization of BisGMA/TEGDMA.}

The FRP of BisGMA/TEGDMA blend in thick films $(1.4 \mathrm{~mm})$ under air and in the presence of the DMs/NPG $(0,5 \% / 1 \%$ w/w) couples is very efficient upon irradiation with the LED@405

nm (Figure 4). Clearly, both the DMs/Iod and DMs/NPG systems have the ability to overcome the oxygen inhibition usually observed in FRP. Typical methacrylate function conversion-time profiles are given in Figure 4 and the FCs are summarized in Table 2. In these irradiation conditions, Iod alone does not work, the same applies to DM or NPG alone, showing the requirement of DM/Iod or DM/NPG for efficient systems. However, it is well obvious that DMs/NPG systems have higher final methacrylate conversions than DMs/Iod (Figure 4, curves 24 vs curves 1-3; see also in Table 2; irradiation with LED@405 nm). This latter behavior can be ascribed to the color of the obtained thick polymer that changed from bright yellow to dark green in the case of the presence of iodonium salt as an additive. Accordingly, an inner filter effect occurs during polymerization in presence of Iod; the phenomenon is not observed in presence of NPG, where the color changes from light yellow to slightly darker yellow.

DM1 and DM2 have the same absorption properties at $\lambda=405 \mathrm{~nm}$ (Figure 1). In addition, they have nearly the same electron transfer quantum yield with Iod ( $\phi_{\mathrm{et}}$; calculated according to eq 2, Table 4 - see below), so they have the same reactivity, and then the same efficiency. Accordingly, the same rates of polymerization in the presence of iodonium salt are found (Figure 4, curves 1-3).

In the presence of NPG, higher methacrylate final conversions were obtained in presence of DM2, suggesting that DM2 is more efficient than DM1 (Figure 4 curves 2-4). 
Table 2. Final Reactive Epoxy Function Conversion (FC) for EPOX and Methacrylate Function for a BisGMA/TEGDMA blend, using Different Photoinitiating Systems after 800s or 100s of Irradiation, Respectively with LED @ 405 nm.

\begin{tabular}{|c|c|c|c|c|c|}
\hline \multirow{2}{*}{\multicolumn{2}{|c|}{$\begin{array}{c}\text { epoxy function conversion (FC) } \\
(\text { at } t=800 \mathrm{~s}) \\
\text { DMs/Iod } \\
\text { (thickness }=25 \mu \mathrm{m}) \\
\text { under air }\end{array}$}} & \multicolumn{4}{|c|}{$\begin{array}{l}\text { methacrylate function conversion (FC) } \\
\qquad(\text { at } t=100 \mathrm{~s})\end{array}$} \\
\hline & & & $\begin{array}{r}\text { DMs/Iod } \\
\text { (thickne } \\
\text { un }\end{array}$ & $\begin{array}{l}\text { DM/NPG } \\
=1.4 \mathrm{~mm}) \\
\text { air }\end{array}$ & \\
\hline DM1/Iod & DM2/Iod & DM1/Iod & DM2/Iod & DM1/NPG & DM2/NPG \\
\hline $\begin{array}{c}52 \%(0.5 \% / 1 \% \\
w / w) ; \\
42 \%(0.3 \% / 1 \% \\
w / w)\end{array}$ & $\begin{array}{c}64 \%(0.5 \% / 1 \% \\
\mathrm{w} / \mathrm{w}) ; \\
56 \%(0.3 \% / 1 \% \\
\mathrm{w} / \mathrm{w})\end{array}$ & $\begin{array}{c}40 \% \\
(0.5 \% / 1 \% \mathrm{w} / \mathrm{w})\end{array}$ & $\begin{array}{c}32 \% \\
(0.5 \% / 1 \% \mathrm{w} / \mathrm{w})\end{array}$ & $\begin{array}{c}56 \% \\
(0.5 \% / 1 \% \mathrm{w} / \mathrm{w})\end{array}$ & $\begin{array}{c}63 \% \\
(0.5 \% / 1 \% \mathrm{w} / \mathrm{w})\end{array}$ \\
\hline
\end{tabular}

A)

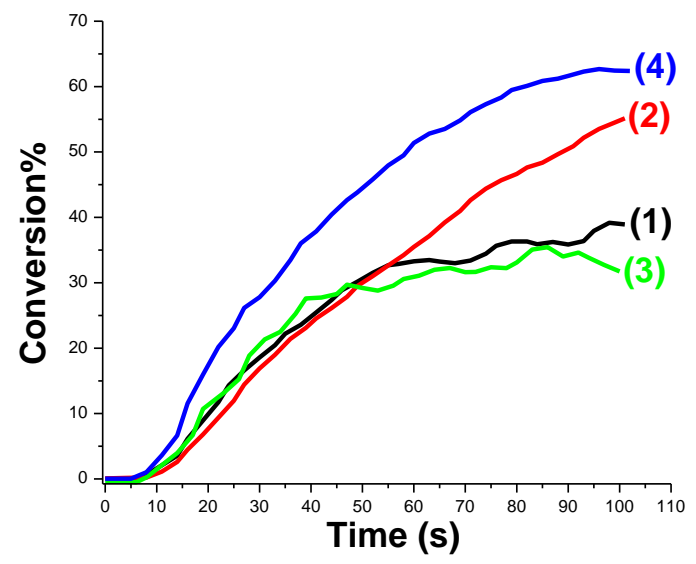

B) After polymerization

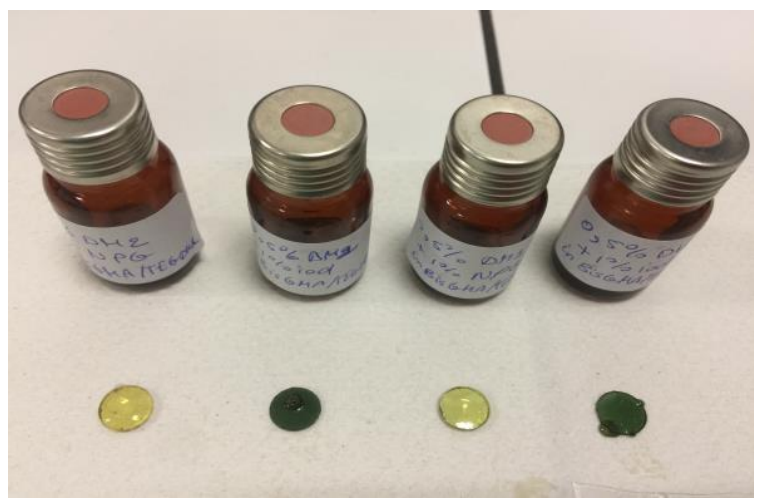

Figure 4. (A) Polymerization profiles (methacrylate function conversion vs. irradiation time) for BisGMA-TEGDMA under air (thickness $=1.4 \mathrm{~mm}$ ) in the presence of the two-component photoinitiating systems: (1) DM1/Iod $(0.5 \% / 1 \% \mathrm{w} / \mathrm{w})$; (2) DM1/NPG $(0.5 \% / 1 \%$ w/w); (3) DM2/Iod (0.5\%/1\% w/w); and (4) DM2/NPG (0.5\%/1\% w/w); upon exposure to LED@405 nm. The irradiation starts at $\mathrm{t}=10 \mathrm{~s}$. (B) Photos of a BisGMA/TEGDMA thick film (1.4 mm) upon irradiation with the LED@405 nm for $100 \mathrm{~s}$ in the presence of DM2/NPG $(0.5 \% / 1 \% \mathrm{w} / \mathrm{w})$, DM2/Iod $(0.5 \% / 1 \% \mathrm{w} / \mathrm{w}), \mathrm{DM} 1 / \mathrm{NPG}(0.5 \% / 1 \% \mathrm{w} / \mathrm{w})$ and DM1/Iod $(0.5 \% / 1 \% \mathrm{w} / \mathrm{w})$, respectively (from left to right), under air after polymerization. The irradiation starts for $\mathrm{t}=10 \mathrm{~s}$. 


\subsection{Laser write experiments and 3D patterns using DM1/NPG System.}

Using laser diode @405nm, laser write examples were successfully performed under air using the DM1/NPG $(0.0625 \% / 0.125 \%$ w/w $)$ system with the BisGMA/TEGDMA resin, which is very reactive in the radical polymerization of methacrylates under air (see above). Remarkably, the high photosensitivity of this resin allows an efficient polymerization process in 3D. Thick samples up to $\sim 2100 \mu \mathrm{m}$ were easily obtained with both high spatial resolution and very short writing time $(<1 \mathrm{~min})$, e.g. "DM1" logo characterized by profilometric experiments using a numerical optical microscope (Figure 5).
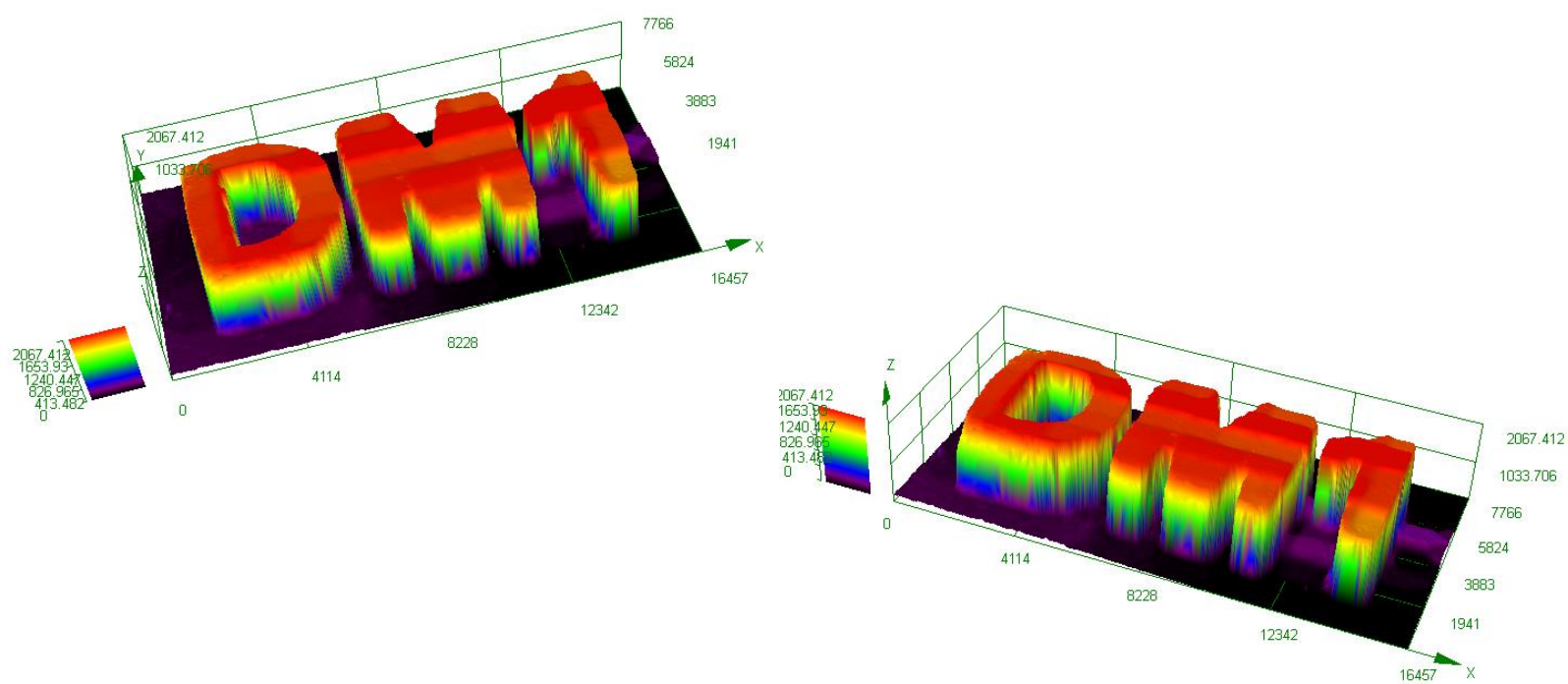

Figure 5. Free radical photopolymerization experiments in laser write experiments: Characterization in 3D by profilometry of the thick sample $(\sim 2100 \mathrm{~mm})$.

\subsection{Access to photocomposites using DM2/NPG system}


As DM2 has shown a high efficiency in both cationic and radical polymerizations, the following section focuses on the use of DM2 in composites which are well known for their improved mechanical properties. Indeed, over the last few years, composite materials have been the dominant emerging materials. They exhibit several properties over conventional ones: light weight, high strength, corrosion resistance and chemical resistance leading to reinforced materials for industrial applications.

In this work, the composites were prepared by impregnation of glass fibers by an organic resin $(50 \%$ glass fibers $/ 50 \%$ resin $\mathrm{w} / \mathrm{w})$ and then irradiating the sample. A fast polymerization was observed using DM2, the results show that DM2/NPG was able to fully cure the composite (glass fibers/methacrylates) in only one pass at the surface and 3 passes on the bottom (for $2 \mathrm{~m} / \mathrm{min}$ belt speed) of irradiation by UV (mercury-Fe doped lamp) lamp (Figure 6) (composite thickness = $2 \mathrm{~mm})$. The results are summarized in Table 3. Furthermore, we note that no significant change of the color of the initial composition was observed using DM2. This behavior demonstrates that DM2 exhibits an outstanding reactivity for the production of composite materials.

Picture before irradiation

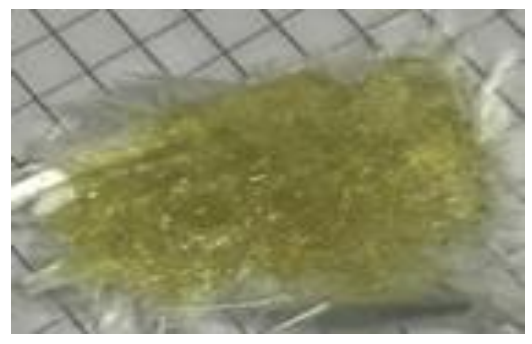

DM2/NPG (0.5\%/1\% w/w) in 1g BisGMA/TEGDMA

\section{Picture after} irradiation

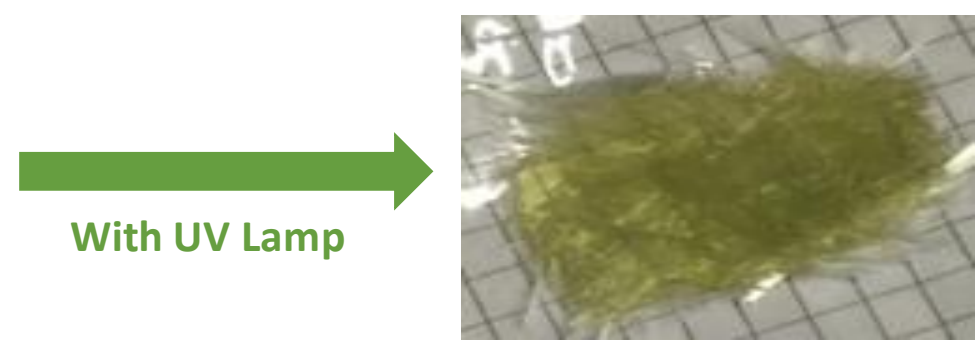

Figure 6. Photocomposites produced using UV conveyor ( $\mathrm{Hg}-\mathrm{Fe}$ doped lamp), Belt Speed = $2 \mathrm{~m} / \mathrm{min}$, using the free radical polymerization (FRP) in the presence of glass fibers $/ \mathrm{resin}(0.5 \%$ $\mathrm{DM} 2+1 \%$ NPG in BisGMA/TEGDMA) (thickness $=2 \mathrm{~mm}$ ). 
Table 3. Number of passes to be tack free for impregnated glass fibers with methacrylate resin using UV conveyor ( $\mathrm{Hg}-\mathrm{Fe}$ doped lamp), belt speed used $=2 \mathrm{~m} . \mathrm{min}^{-1}$.

\begin{tabular}{|c|c|c|}
\hline $\begin{array}{c}\mathbf{5 0 \%} \\
\text { methacrylate resin }\end{array}$ & At the surface & On the bottom \\
\hline $\begin{array}{c}0.5 \% \mathrm{DM} 2+1 \% \mathrm{NPG} \text { in } \\
\text { BisGMA/TEGDMA }\end{array}$ & T.F. after 1 pass & T.F. after 3 passes \\
\hline
\end{tabular}

T.F.: Tack-free

\subsection{Chemical Mechanisms.}

\subsubsection{Steady State Photolysis.}

Steady state photolysis experiments have been carried out. The photolysis of DM2/Iod in acetonitrile upon irradiation with a LED@375 nm is much faster than that of DM2 alone [e.g., DM2/Iod in Figure 7A vs. DM2 alone in Figure 7B]. A new photoproduct (characterized by a significant visible light absorption) is formed according to the DM2/Iod interaction. An isobestic point at about $340 \mathrm{~nm}$ is found in the DM2/Iod photolysis suggesting that no other by-side reaction occurs. The effect of Iod on the DM2 photolysis is clearly shown in Figure 7C, where the optical density@375 nm for different irradiation times is depicted (curve 2 in presence of Iod vs. curve 1 without Iod). 
(A)

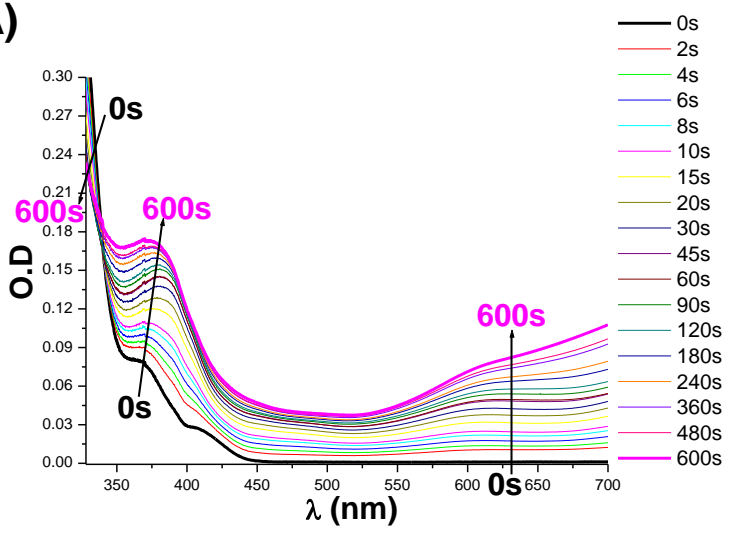

(B)

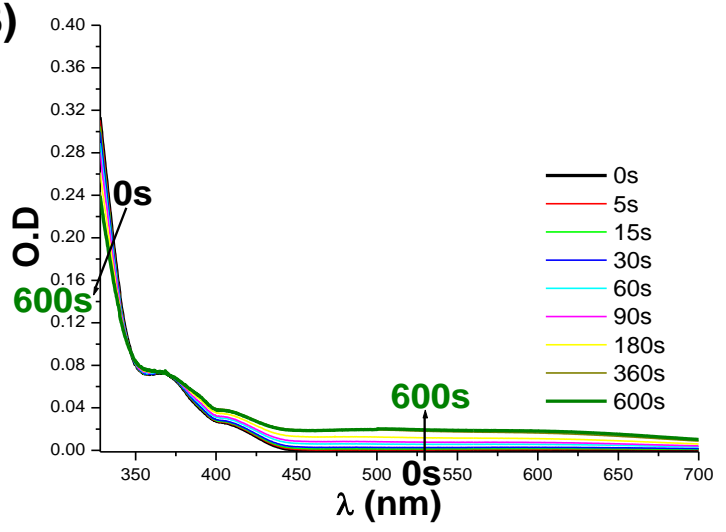

(C)

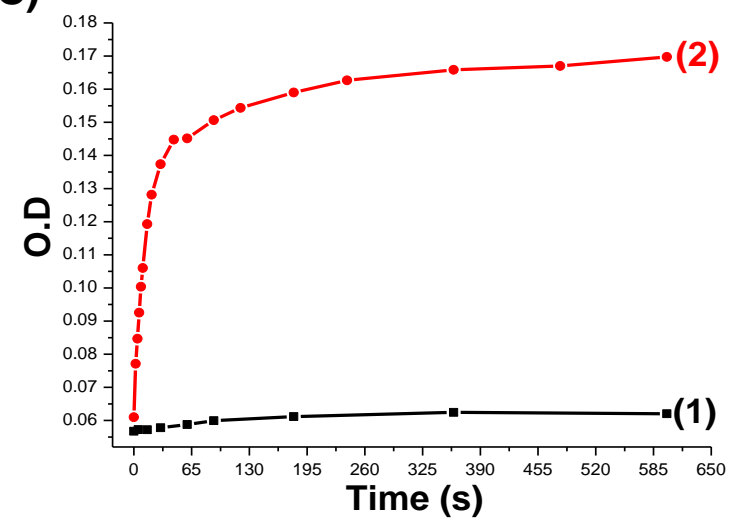

Figure 7. (A) DM2/Iod photolysis upon exposure with LED@ $375 \mathrm{~nm}$; and (B) Photolysis of DM2 in absence of Iod. (C) Formation of photoproducts without (1) and with (2) Iod salt vs time of irradiation with a LED@375 nm.

\subsubsection{Fluorescence quenching, Cyclic Voltammetry and ESR Experiments}

Fluorescence quenching experiments in acetonitrile for DM2 are shown in Figures 8A and 8B. First, the crossing point of the absorption and fluorescence spectra allows the determination of the first singlet excited state energy $\left(E_{S 1}\right.$, Table 4). 
A)

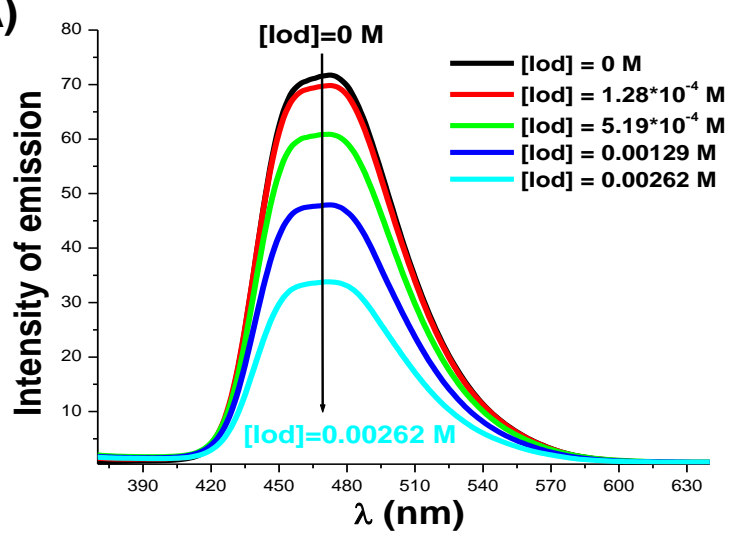

B)

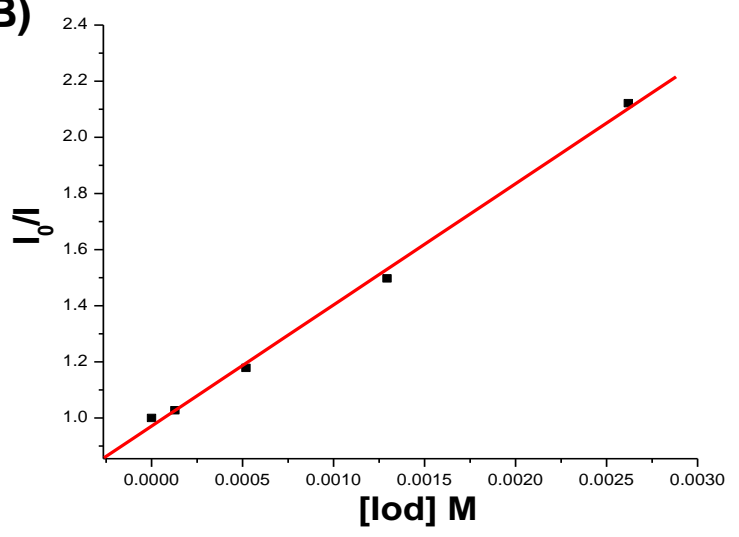

Figure 8. (A) Fluorescence quenching of DM2/Iod; and (B) Stern-Volmer treatment for the DM2/Iod fluorescence quenching.

Table 4. Parameters Characterizing the (Photo)Chemical Mechanisms Associated with ${ }^{1,3} \mathrm{DMs} / \mathrm{Iod}$ in Acetonitrile.

\begin{tabular}{|c|c|c|c|c|c|c|c|}
\hline & $\begin{array}{c}\text { Ex }_{\text {ox }} \\
(\mathrm{eV})\end{array}$ & $E_{S 1}(e V)$ & $\begin{array}{c}\Delta \mathbf{G}_{\text {et }(\mathbf{S} \mathbf{1})} \\
(\mathbf{e V})\end{array}$ & $\begin{array}{c}\mathbf{K}_{\mathbf{S V}} \\
\left(\mathbf{M}^{-1}\right)\end{array}$ & $\phi_{\text {et(S1) }}$ & $E_{T 1}(e V)$ & $\begin{array}{c}\Delta \mathbf{G}_{\text {et(T1) }} \\
(\mathbf{e V})\end{array}$ \\
\hline DM1/Iod & 0.40 & 2.95 & -2.35 & 302 & 0.85 & 2.62 & -2.02 \\
\hline DM2/Iod & 0.38 & 2.96 & -2.38 & 432 & 0.89 & 2.6 & -2.03 \\
\hline
\end{tabular}

Favorable fluorescence quenching processes of the excited singlet states by Iod are shown by the high value of the Stern-Volmer coefficients (Ksv; Table 4), high electron transfer quantum yield ( $\phi_{\mathrm{et}}$; calculated according to eq 2 , Table 4 ) as well as highly favorable free energy changes $\left(\Delta \mathrm{G}_{\mathrm{et}}\right)$ for the expected electron transfer reaction between the DMs and Iod (reactions $\mathrm{r} 1$ and $\mathrm{r} 2$; e.g. for DM2/Iod, $\Delta \mathrm{G}_{\mathrm{et}(\mathrm{S} 1)}=-2,38 \mathrm{eV}$; see in Table 4; the potential of the first oxidation peak of DMs are determined by cyclic voltammetry (for DM2; $\mathrm{E}_{\mathrm{ox}} \sim 0.38 \mathrm{~V}$, see Table 4 ).

$$
\phi_{\mathrm{et}}=\mathrm{K}_{\mathrm{sv}}[\operatorname{Iod}] /\left(1+K_{\mathrm{sv}}[\operatorname{Iod}]\right) \quad(\text { eq 2) }
$$




\begin{tabular}{|ll|}
\hline $\mathrm{DM} 2 \rightarrow{ }^{*} \mathrm{DM} 2(\mathrm{~h} v)$ & (r1) \\
${ }^{*} \mathrm{DM} 2+\mathrm{Ph}_{2} \mathrm{I}^{+} \rightarrow \mathrm{DM}^{\bullet+}+\mathrm{Ph}_{2} \mathrm{I}^{\bullet} \rightarrow \mathrm{DM}^{\bullet+}+\mathrm{Ph}^{\bullet}+\mathrm{PhI}$ & $(\mathrm{r} 2)$ \\
$\mathrm{DM} 2{ }^{\bullet+}+\mathrm{EPOX} \rightarrow$ cationic polymerization & (r3) \\
$\mathrm{Ph}^{\bullet}+\mathrm{BisGMA} / \mathrm{TEGDMA} \rightarrow$ radical polymerization & (r4)
\end{tabular}

Scheme 2. Proposed chemical mechanisms for photopolymerization initiated by DMs (DM1 or DM2). !!! mettre Ar2I+ au lieu de Ph2I+ et modifier $\mathrm{r} 4$ avec $\mathrm{Ar}^{\circ}$; enlever le surligné bleu

A triplet state pathway cannot be ruled out i.e. the free energy change $\left(\Delta \mathrm{G}_{\mathrm{et}(\mathrm{T} 1)}\right)$ for the electron transfer reaction ${ }^{3} \mathrm{DM} 2 / \mathrm{Iod}$ is also favorable $\left(\Delta \mathrm{G}_{\mathrm{et}(\mathrm{T} 1)}=-2.03 \mathrm{eV}\right.$ is less favorable than $\Delta \mathrm{G}_{\mathrm{et}(\mathrm{S} 1)}=-2.38 \mathrm{eV}$; see Table 4).

The favorable quenching process of DMs by Iod is schematized with the reactions $\mathrm{r} 1$ and $\mathrm{r} 2$ (Scheme 4). This is also fully confirmed by ESR results. Indeed, the aryl radicals $\left(\mathrm{Ar}^{\bullet}\right)$ were easily detected as $\mathrm{PBN} / \mathrm{Ar}^{\bullet}$ radical adducts in the irradiated DM2/Iod solution in ESR-ST experiments (Figure 9A). Indeed, the simulation of the experimental ESR spectrum yields the hyperfine coupling constants $(\mathrm{hfcs}): \mathrm{a}_{\mathrm{N}}=14,09 \mathrm{G}$ and $\mathrm{a}_{\mathrm{H}}=2.09 \mathrm{G}$ typical for the PBN/Ar ${ }^{\bullet}$ radical adducts [31,32]. Remarkably, the aryl radicals are the best reported carbon centered initiating species for addition onto methacrylate double bond $\left(\mathrm{k}_{\mathrm{add}} \sim 10^{8} \mathrm{M}^{-1} \cdot \mathrm{s}^{-1}\right)$ [2] in full agreement with the good efficiency of the DMs/Iod couples as radical initiators ( $r 4$ in Scheme 4).

On other side, the radical cations $\left(\mathrm{DM}^{\bullet+}\right)$ were easily detected in the irradiated DM2/Iod system (Figure 9B), where no spin trapping agent (PBN) was used to avoid detecting any additional aryl radical. The ESR spectrum of DM2 ${ }^{\bullet+}$ consists of broad line pattern at $\mathrm{g}=2.0027$. 
$\mathrm{Ar}^{\bullet}$ and $\mathrm{DM} 2{ }^{\bullet+}$ can be considered as the initiating species for the radical polymerization and the cationic polymerization, respectively (Scheme 4). Alternatively, in presence of radical cations, the release of initiating Bronsted acid for CP [34] can also be observed.
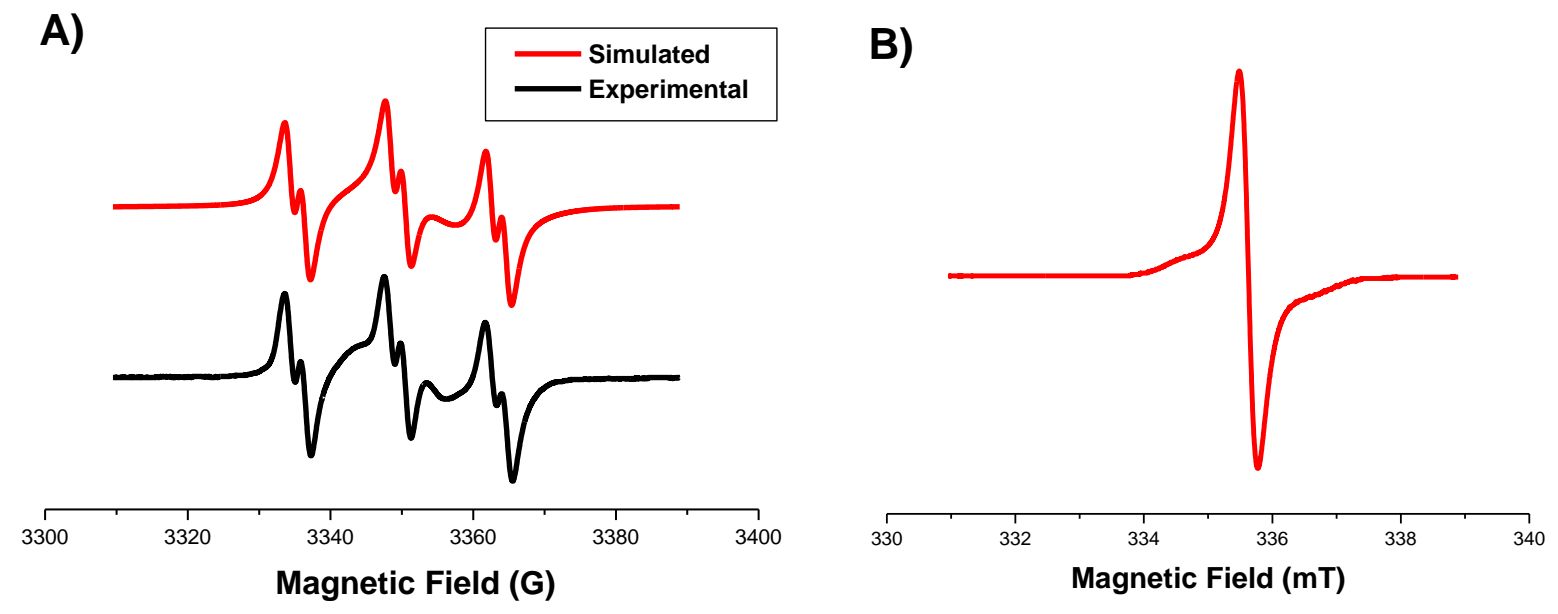

Figure 9. (A) ESR-ST spectra obtained upon irradiation (LED@405nm) of DM2/Iod/PBN, experimental (lower spectrum), and simulated (upper spectrum) in tert-butyl benzene as a solvent; and (B) ESR spectrum obtained upon irradiation (LED@ $405 \mathrm{~nm}$ ) for DM2/Iod solution in absence of spin trapping agent (solvent $=$ tert-butyl benzene).

\subsubsection{Structure/Reactivity/ Efficiency Relationship}

DM1/Iod exhibits a rather similar performance than DM2/Iod in radical polymerization, this can be ascribed to the same absorption properties at @ 405 nm i.e. DM1 and DM2 have the same extinction coefficient at this wavelength. In addition, they have nearly the same electron transfer quantum yield ( $\phi_{\mathrm{et}}$; calculated according to eq 2 , Table 4 ), so they have the same reactivity, and then the same efficiency (Figure 4, curves 1-3).

For the reaction DMs/NPG, a higher reactivity is found for DM2 suggesting a more favorable reduction process for this latter compound. 
Both DM1 and DM2 have high and rather similar extinction coefficients at $405 \mathrm{~nm}$ (see Table 1) and nearly the same electron transfer quantum yield. In contrast, DM2/Iod has higher performance than DM1/Iod in cationic processes (Figure 3). Therefore, this suggests that the initiating ability of $\mathrm{DM} 1{ }^{\bullet+}$ for the polymerization of EPOX is lower than for DM2 ${ }^{\bullet+}$.

\section{Conclusion:}

In summary, we designed and developed new photoinitiators based on the carbazole structure (DMs). DMs have strong visible light absorptions and can be very efficient for cationic and radical polymerizations upon violet and blue LEDs. Remarkably, DM2 can be selected as the best PI compared to DM1 for its highest performance in initiating both radical and cationic polymerizations. The high performance of DMs in radical initiating systems is also shown for new 3D printing resins. The proposed system can be used for the production of thick glass fibers composites. The development of other high-performance photosensitive resins for 3D printing of composites is under way and will be presented in forthcoming papers.

\section{ACKNOWLEDGMENTS}

The Lebanese group would like to thank "The Association of Specialization and Scientific Guidance" (Beirut, Lebanon) for funding and supporting this scientific work. All the authors thank the Agence Nationale de la recherche (ANR) for the grant "FastPrinting". 


\section{REFERENCES}

[1] Fouassier J.P., Rabek J.C., Radiation curing in polymer science and technology, London: Elsevier; 1993.

[2] Fouassier, J.P., Lalevée J., Photoinitiators for Polymer Synthesis, Scope, Reactivity, and Efficiency; Wiley-VCH Verlag GmbH \& Co.KGaA: Weinheim, Germany, 2012.

[3] Fouassier, J.P., Photoinitiator, Photopolymerization and Photocuring: Fundamentals and Applications; Gardner Publications: New York, 1995.

[4] Dietliker, K.A., Compilation of Photoinitiators Commercially Available for UV Today; Sita Technology Ltd.: London, 2002.

[5] Davidson S., Exploring the Science, Technology and Application of UV and EB Curing; Sita Technology Ltd.: London, 1999.

[6] Crivello J.V., Dietliker K., Bradley G., Photoinitiators for Free Radical Cationic \& Anionic Photopolymerisation; John Wiley \& Sons: Chichester, U.K., 1999.

[7] Dietlin C., Schweizer S., Xiao P., Zhang J., Morlet-Savary F., Graff B., Fouassier J.P., Lalevée J., Photopolymerization upon LEDs: New Photoinitiating Systems and Strategies. Polym. Chem. 2015, 6 (21), 3895-3912, 10.1039/C5PY00258C.

[8] Treat N.J., Fors B.P., Kramer J.W., Christianson M., Chiu C.Y., Read de Alaniz J., Hawker C.J., Controlled Radical Polymerization of Acrylates Regulated by Visible Light, ACS Macro Lett., 2014, 3 (6), 580-584.

[9] Pan X., Lamson M., Yan J., Matyjaszewski K., Photoinduced Metal-Free Atom Transfer Radical Polymerization of Acrylonitrile, ACS Macro Lett., 2015, 4 (2), 192-196. 
[10] Boyer C., Corrigan N.A., Jung K., Nguyen D., Nguyen T.K., Adnan N.N., Oliver S., Shanmugam S., Yeow J., Copper-Mediated Living Radical Polymerization (Atom Transfer Radical Polymerization and Copper(0) Mediated Polymerization): From Fundamentals to Bioapplications, Chem. Rev., 2016, 116 (4), 1803-1949.

[11] Tasdelen M.A., Yilmaz G., Iskin B., Yagci Y., Photoinduced Free Radical Promoted Copper(I)-Catalyzed Click Chemistry for Macromolecular Syntheses, Macromolecules, 2012, 45 (1), 56-61.

[12] Corrigan N., Xu J., Boyer C., A Photoinitiation System for Conventional and Controlled Radical Polymerization at Visible and NIR Wavelengths, Macromolecules, 2016, 49 (9), $3274-3285$.

[13] Yeow J., Shanmugam S., Corrigan N., Kuchel R.P., Xu J., Boyer C., A PolymerizationInduced Self-Assembly Approach to Nanoparticles Loaded with Singlet Oxygen Generators, Macromolecules, 2016, 49 (19), 7277-7285.

[14] Kim D., Stansbury J.W., A Photo-Oxidizable Kinetic Pathway of Three-Component Photoinitiator Systems Containing Porphrin Dye (Zn-TPP), an Electron Donor and Diphenyl Iodonium Salt, J. Polym. Sci., Part A: Polym. Chem. 2009, 47 (12), 3131-3141.

[15] Chen Y., Yamamura T., Igarashi K.J., J. Polym. Sci. Polym. Chem., 2000, 38, 90.

[16] Hua Y., Crivello J.V., In: Photoinitiated polymerization, ACS Symposium Series, Belfield and Crivello Ed, 2003, 847, 219 (Chapter 19).

[17] Hua Y., Crivello J.V., J. Polym. Sci., Part A: Polym. Chem. 2000, 38, 3697. 
[18] Lazauskaite R., Grazulevicius J.V., In: Handbook of photochemistry and photobiology, H.S. Nolwl Ed, 2003, 335.

[19] Yagci Y., Reetz I., Externally stimulated initiator systems for cationic polymerization, Prog. in Polym. Sci., 1998, 23, 1485-1538.

[20] Shaikh Mohammed J., Applications of 3D printing technologies in Oceanography, Elsevier, 2016, 17, 97-117.

[21] Liu Z., Zhang M., Bhandari B., Wang Y., 3D printing: Printing precision and application in food sector, Elsevier, 2017, 69, 83-94.

[22] Ballard D.H., Trace A.P., Ali S., Hodgdon T., Zygmont M.E., DeBenedectis C.M., Smith S.E., Richardson M.L., Patel M.J., Decker S.J., Lenchik L., Clinical Applications of 3D Printing: Primer for Radiologists, 2018, 25 (1), 52-65.

[23] Mironov V., Boland T., Trusk T., Forgacs G., Markwald R.R., Organ Printing: computeraided jet-based 3D tissue engineering, 2003, 21 (4), 157-61.

[24] Reference Module in Materials Science and Materials Engineering, Comprehensive Composite Materials II, Composites in Sports Applications, 2018, 3, 469-526.

[25] Besisa D.H.A., Ewais E.M.M., Ahmed Y.M.Z., Elhosiny F.I., Kuznetsov D.V., Fend T., Densification and characterization of SiC-AIN composites for solar energy applications, Elsevier, 2018, 129, 201-213.

[26] Balasubramanian K., Sultan M.T.H., Rajeswari N., Sustainable Composites for Aerospace Applications, Manufacturing techniques of composites for aerospace applications, 2018, 55-67. 
[27] Komus A., Beley N., Reference Module in Materials Science and Materials Engineering, Comprehensive Composite Materials II, Composite Applications For Ground Transportation, $2018,3,420-438$.

[28] Yadav S., Gangwar S., Singh S., Micro/Nano Reinforced Filled Metal Alloy Composites: A Review Over Current Development in Aerospace and Automobile Applications, Part E, 2017, 4 (4), 5571-5582.

[29] Bui T.T., Shah S.K., Abbas M., Sallenave X., Sini G., Hirsch L., Goubard F., CarbazoleBased Molecular Glasses as Hole-Transporting Materials in Solid State Dye-Sensitized Solar Cells, ChemNanoMat, 2015, 1(3), 203-210.

[30] Lalevée J., Blanchard N., Tehfe M.A., Peter M., Morlet-Savary F., Gigmes D., Fouassier J.P., Polym. Chem. 2011, 2, 1986-1991.

[31] Lalevée J., Blanchard N., Tehfe M.A., Morlet-Savary F., Fouassier J.P., Green Bulb Light Source Induced Epoxy Cationic Polymerization under Air Using Tris(2,2'bipyridine)ruthenium(II) and Silyl Radicals, Macromolecules, 2010, 43 (24), 10191-10195.

[32] Lalevée J., Blanchard N., Tehfe M.A., Peter M., Morlet-Savary F., Gigmes D., Fouassier J.P., Efficient Dual Radical/Cationic Photoinitiator under Visible Light: A New Concept, Polym. Chem., 2011, 2 (9), 1986-1991.

[33] Rehm D., Weller A., Kinetics of Fluorescence Quenching by Electron and H-Atom Transfer, Isr. J. Chem. 1970, 8 (2), 259-271. 
[34] Budreckiene R., Lazauskaite R., Buika G., Grazulevicius J.V., Cationic photopolymerization of carbazolyl-containing vinyl ethers, J. Photochem. and Photobio. A Chem., 2003, 157 (1), 117 123. 


\section{TOC Graphic:}

Photoinitiators for 3D printing and Composites

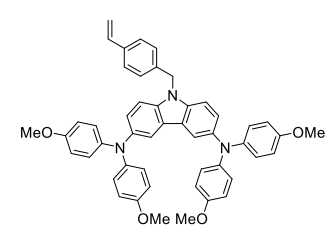

DM1

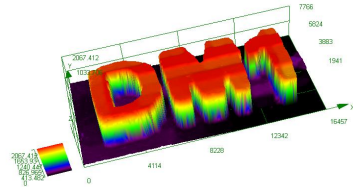

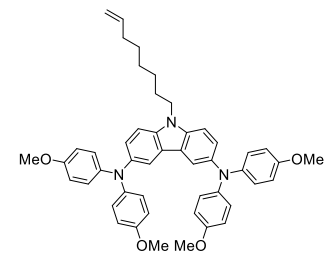

DM2

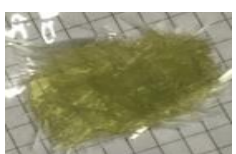

